\title{
Sexual exhaustion and recovery of masculine copulatory behavior in virilized female rats
}

RICHARD E. WHALEN AND RICHARD T. ROBERTSON, DEPARTMENT OF PSYCHOBIOLOGY, UNIVERSITY OF CALIFORNIA, Irvine, Calif. 92664

When allowed to mate to sexual satiation the male rat displays systematic changes in the frequency and timing of intromission and ejaculation responses. Female rats genitally virilized by preand early post-natal androgen stimulation display the same sequence of changes in masculine behavior as shown by males.

In 1942 Beach and Rasquin concluded that the female rat possesses the neuromotor organization necessary for the execution of masculine copulatory behavior. This conclusion was based on observations of male-type mounting behavior, by intact and ovariectomized female rats. These responses consisted of mounts without pelvic thrusting, mounts with pelvic thrusting, and mounts with thrusting plus the intromission reflex, a deep vigorous thrust followed by a rapid withdrawal from the stimulus female. Exogenous testosterone treatment increases the total mount frequency and the probability of intromission (Beach, 1942). In the male rat the intromission reflex normally occurs when the penis is inserted into the vagina. In these early studies the occurrence of the male's characteristic ejaculation reflex was not observed. The present report describes the frequency and timing of male-type copulatory responses, including the ejaculation reflex in female rats which were genitally masculinized by pre- and early post-natal stimulation by testosterone.

When the male is placed with a receptive female he will execute a series of mounts with pelvic thrusting, most of these resulting in intromission. Following a series of mounts with intromission, the ejaculation reflex will occur, the first ejaculation occurring after approximately 11 intromissions. Following ejaculation a nonmating interval of approximately $5 \mathrm{~min}$ will occur before mating resumes. The second ejaculation will occur after fewer intromissions (6-7) and the second post-ejaculatory interval will be longer than the first. Normally the male will achieve 6-7 ejacualtion responses before mating ceases (Beach \& Jordan, 1956).

Following such a sexual exhaustion test the male rat is unlikely to mate $24 \mathrm{~h}$ later. If the male is tested four days after exhaustion, mating will occur but the exhaustion criterion will be reached after fewer intromissions and ejaculations than were displayed on the initial test. After two weeks without mating, the male rat will again display 6-7 ejaculations and approximately 35-40 intro-
Table 1

Characteristic Response Frequencies Preceding Sexual Exhaustion in Rats

\begin{tabular}{llcc}
\multicolumn{1}{c}{ Study } & Sex & $\begin{array}{c}\text { Mean Ejaculation } \\
\text { Frequency }\end{array}$ & $\begin{array}{c}\text { Mean Intromission } \\
\text { Frequency }\end{array}$ \\
\hline Beach \& Jordan (1956) & Male & 6.9 & 41.7 \\
Fisher (1958) & Male & 6.9 & 43.0 \\
Fowler \& Whalen (1961) & Male & 5.8 & 34.6 \\
Present & Female & 6.0 & 35.6 \\
\hline
\end{tabular}

missions before reaching exhaustion (Beach \& Jordan, 1956). The present observations show that the hormonally virilized female rat will exhibit a pattern of sexual exhaustion and recovery of masculine behavior which parallels that shown by the male.

Subjects and Procedures. The Ss were five, 150-day-old Long-Evans female rats raised in the laboratory. The mothers of these females were administered $2 \mathrm{mg} /$ day testosterone propionate (TP) on Days 16-20 of pregnancy, and the pups themselves received a direct subcutaneous injection of $1 \mathrm{mg}$ TP $96 \mathrm{~h}$ after birth. Such treatment produces females with no external vaginal orifice and with a hypertrophied phallus. The animals were ovariectomized at approximately 60 days of age and administered $1 \mathrm{mg}$ TP daily. The tests for sexual exhaustion and recovery described here occurred after the animals had been receiving $1 \mathrm{mg}$ TP daily for two months. For each test a single virilized female was placed in a cylindrical glass observation cage and allowed to adapt for $15 \mathrm{~min}$. A sexually receptive stimulus female was then placed in the arena and the two females were allowed to mate until the exhaustion criterion of $30 \mathrm{~min}$ without an intromission response by the virilized female was met. The $O$ recorded the frequency and timing of each mount with intromission and each ejaculation response. Following satiation the virilized females were retested to the same criterion 48 and $192 \mathrm{~h}$ after the initial test.

Results and Discussion. Table 1 shows that the virilized females reached the exhaustion criterion on the first test after displaying an average of 35.6 intromission responses and 6.0 ejaculation responses. These values are comparable to those normally obtained from males as is shown in Table 1 .

Figure 1 compares the timing of the first six ejaculations and the frequency of intromissions preceeding successive ejaculations of our virilized females with comparable data reported by Beach \& Jordan (1956) for males. As can be seen, the frequency and timing of intromission and ejaculation responses were comparable. As with the males, the virilized females showed a progressive decline

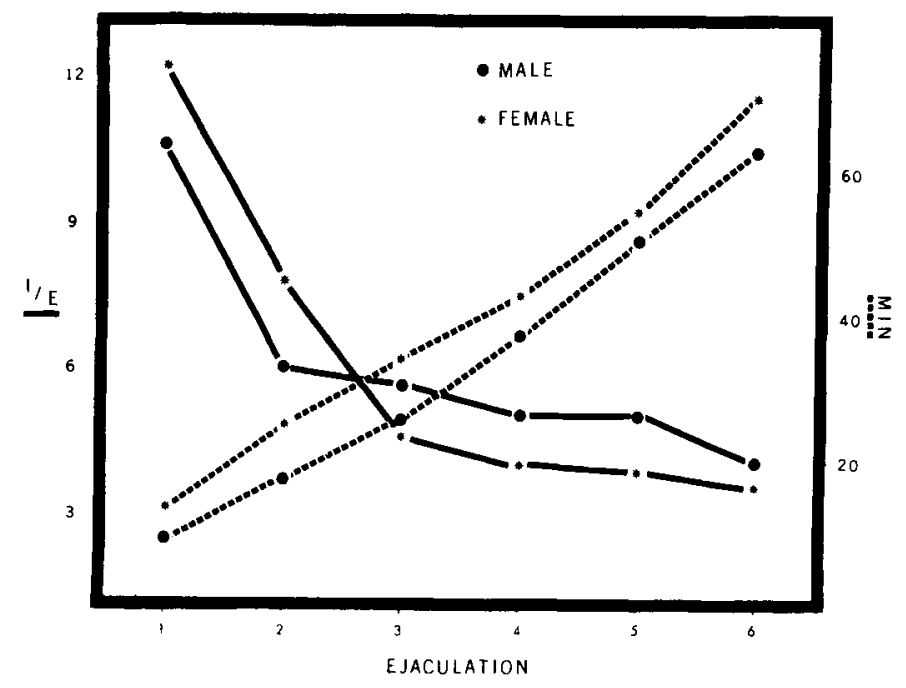

Fig. 1. Mean intromission frequency preceding successive ejaculations (I/E) and timing of successive ejaculations (MIN.) before sexual satiation for male and hormonally virilized female rats. Data for male rats taken from Beach \& Jordan (1956). The dotted line represents minutes after the start of the mating test at which each successive ejaculation response occurred. Solid lines represent the number of intromission responses which preceded each ejaculation response. 
in intromission frequency preceding successive ejaculations and successive ejaculations were spaced progressively farther apart.

On the first post-exhaustion test $48 \mathrm{~h}$ after the initial test no virilized female mated. On the second post-exhaustion test eight-days after the initial test all females mated and reached exhaustion after an average of 4.2 ejaculations and 26.4 intromission responses. Both of these values represent significant reductions from initial levels in ejaculation frequency $(F=81.0$, $\mathrm{df}=1 / 4, \mathrm{p}<.01)$ and intromission frequency $(\mathrm{F}=12.6, \mathrm{df}=1 / 4$, $\mathrm{p}<.05)$, before sexual satiation indicating that the virilized females had not returned to initial levels even after eight days of sexual inactivity.

The present findings support and extend Beach's observations that the female rat possesses a neuromotor control system for the execution of masculine responses. It is possible to hypothesize that in the present case the early androgen stimulation served to "organize" those neural centers which mediate male-type behavior as some experiments on the effects of early androgen stimulation would indicate (Grady, Phoenix, \& Young, 1965). It is also possible to suggest that the primary effect of the early androgen stimulation was on the development of a phallus in the female large enough to permit the frequent intromissions which are necessary to produce the ejaculation response. This latter conclusion is consistent with our current and earlier work on the effects of early androgen stimulation (Whalen \& Edwards, 1967).

\section{REFERENCES}

BEACH, F. A. Male and female mating behavior and pre-puberally castrated female rats treated with androgens. Endocrinology, 1942, 31, 673-678.

BEACH, F. A., \& RASQUIN, P. Masculine copulatory behavior in intact and castrated female rats. Endocrinology, 1942, 31, 393-409.

BEACH, F. A., \& JORDAN, L. Sexual exhaustion and recovery in the male rat. Quart. J. exp. Psychol, 1956, 8, 121-133.

FISHER, A. E. Effects of stimulus variation on sexual satiation in the male rat. Amer. Psychologist, 1958, 13, 382.

FOWLER, H., \& WHALEN, R. E. Variation in incentive stimulus and sexual behavior in the male rat. J. comp. physiol Psychol, 1961, 54, 68-71.

GRADY, K. L., PHOENIX, C. H., \& YOUNG, W. C. Role of the developing rat testis in differentiation of the neural tissues mediating mating behavior. J. comp. physiol PsychoL, 1965, 59, 176-182.

WHALEN, R. E., \& EDWARDS, D. A. Hormonal determinants of the development of masculine and feminine behavior in male and female rats. Anat. Rec., 1967, 157, 173-180.

\section{NOTE}

1. Supported by research grant HD-00893 to REW from the National Institute of Child Health and Human Development and a training fellowship USPH MH 11095-01 to RTR from the NIMH. The hormones were generously supplied by P. Perlman of the Schering Corp. As used in this paper the ejaculation response is a behaviorally distinct response and its occurrance does not necessarily imply the emission of semen. 